\title{
DYNAMIC RESPONSE OF A ROAD BRIDGE SUBJECTED TO PASSING A HEAVY VEHICLE OVER A STANDARD IRREGULARITY - NUMERICAL MODELLING AND EXPERIMENTAL TESTING
}

\author{
Milan Moravčík \\ Faculty of Civil Engineering, University of Zilina, Zilina, Slovakia \\ *E-mail of corresponding author: mimo@fstav.uniza.sk
}

\section{Resume}

The paper presents an analysis of an actual problem related to dynamic effects to road bridges due to travelling a heavy vehicle over the bridge. Numerical simulations of the dynamic response are applied on a fictitious simple beam of the length $L_{b}=52 \mathrm{~m}$ with an artificial irregularity at midspan, corresponding to a characteristic span $L_{(b 5)}=52 \mathrm{~m}$ of the ten-span continuous box girder bridge. A heavy four-axle truck $m_{v}=32 \mathrm{t}$ is used for dynamic excitation, travelling over the bridge at passing speed of $70 \mathrm{~km} / \mathrm{h}$. The obtained results are compared to results of the experimentally tested ten-span continuous pre-stressed reinforced concrete girder bridge at the same speed.

\section{Article info}

Received 5 May 2021

Accepted 21 June 2021

Online 27 October 2021

\section{Keywords:}

dynamic bridge deflection, moving vehicle load, modal superposition, numerical simulation, dynamic testing

\section{Introduction}

Nowadays, one of the current problems in bridge engineering is evaluation of the dynamic response due to the intensive passages of heavy trucks and lorries over the bridge. This paper deals with validation of a simplified numerical modelling of a dynamic response of a bridge structure, induced by passing of a heavy truck vehicle over an artificial standard irregularity. Numerical modelling, as well as dynamic load tests of a heavy vehicle crossings over a bridge with the standard irregularity at mid-span [1], is an important procedure for checking the dynamic behavior and quality of a bridge structure under intense dynamic loading. Numerical simulations were created for a characteristic span $L_{(b i)}=52 \mathrm{~m}$ of the ten-span continuous box girder road bridge, modelled as a fictive simple beam associated to the characteristic span. This field has been experimentally tested for crossing of a heavy truck at the speed of $70 \mathrm{~km} / \mathrm{h}$. The overall view of the tested bridge is shown in Figure 1.

The solution of deflections of mid-span was obtained by application the linear theory of solving the motion equation, giving the beam deflection as a function of time [2-3]. The purpose of the numerical modelling has been:

(1) To verify the proposed simplified solution of the dynamic response for a characteristic span of a continuous bridge structure, which is currently used the most, as a response of the fictive simple beam;

(2) To evaluate the intense dynamic response due to the moving of a heavy truck as an impact of the impulse load arising on the irregularity.

\section{Numerical model}

The simplified interaction model vehicle bridge is schematically shown in Figure 2a. The loading vehicle, used for dynamic excitation of the bridge is a four-axle heavy truck of the weight $m_{v}=32 \mathrm{t}$ travelling over the bridge at speed $70 \mathrm{~km} / \mathrm{h}$, shown in Figure $2 \mathrm{~b}$.

\section{Physical modelling and formulation}

The dynamic deflection of the simple bridge $L_{b}=52 \mathrm{~m}$ at mid-span, due to moving an axle mass $m_{v i}$ crossing over the bridge at a speed $c$, obtained by superposition of a force vibration of a simple beam ${ }^{(c)} w_{(1),\left(F_{v i}\right)}\left(L_{b} / 2, t\right)$ considering the first mode $j=1$ only, subjected to a moving load $F_{v i}$ and the impulse effect on the irregularity ${ }^{(c)} w_{\left(M_{0}\right),(I F v i v e l)}(t)$. 


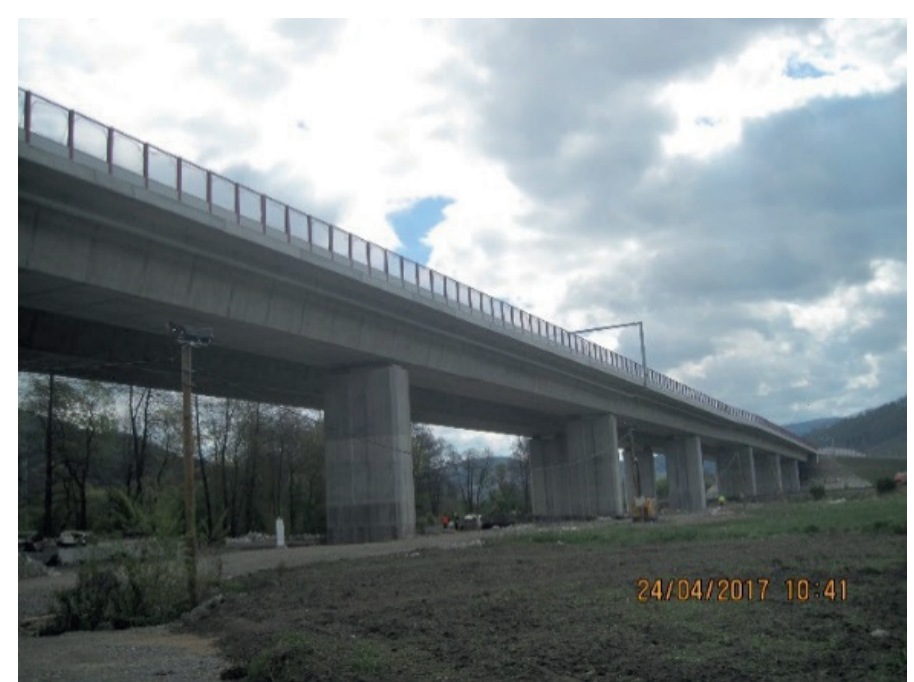

Figure 1 Overall view of the tested ten-spam continuous concrete box-girder bridge

a) Moving of a heavy truck over a fictive simple beam bridge corresponding to a characteristic span $L_{(b 5)}=52 \mathrm{~m}$ of the ten-span continuous bridge
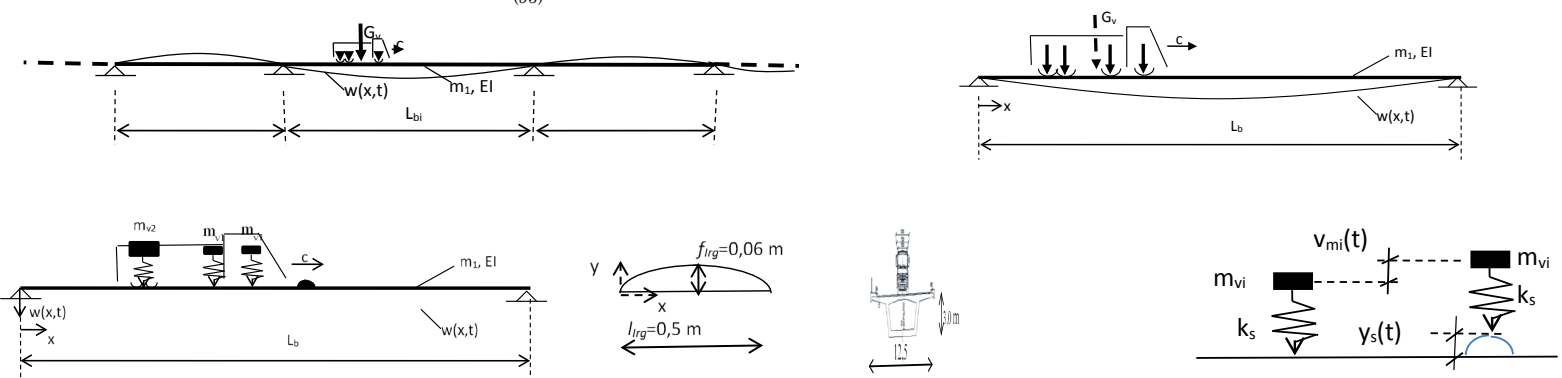

Superposition: The moving load model + the modelling of effect of the standard irregularity
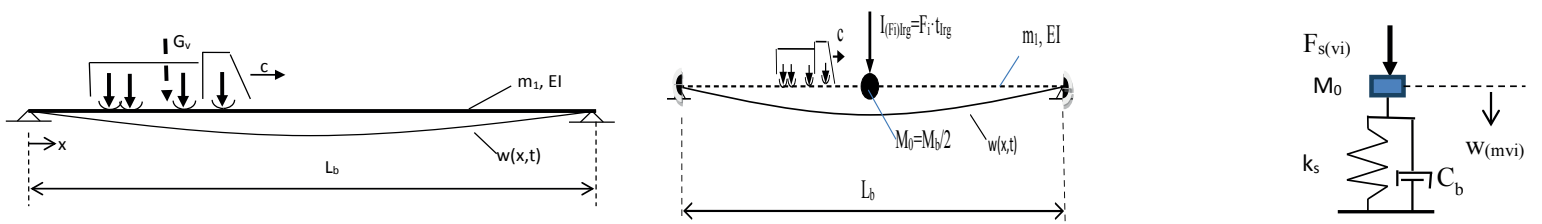

b) Loading model - the whole heavy truck model

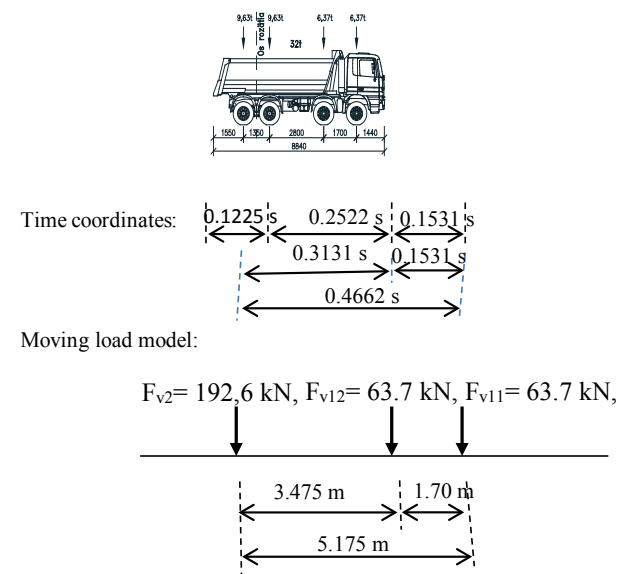

Moving load model:

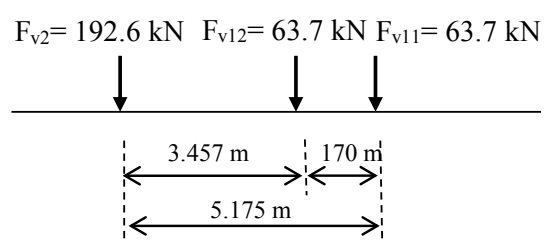

Figure 2 Schematic representation of the simplified dynamic analysis of a road bridge (due to crossing of a heavy car) 
${ }^{(c)} w_{\left(F_{v i}+I F_{v i} V e l\right)}\left(L_{b} / 2, t\right)={ }^{(c)} w_{(1),\left(F_{v i}\right)}\left(L_{b} / 2, t\right)+$

$+{ }^{(c)} w_{(M 0),(I F v i \text { Vel })}(t)$.

\subsection{Moving load problem - the dynamic deflection ${ }^{(c)} w_{(1),\left(F_{v i}\right)}\left(L_{b} / 2, t\right)$ of the simple beam}

The generally used method of modal superposition, together with use of the convolution integral, gives the closed form solution of the vertical dynamic displacements of the beam. This solution gives results that well correspond to the evaluated measurements of a dynamic response on real bridges of various structural arrangements. The beam is assumed to be of the Bernoulli-Euler type, Figure 3.

The beam displacement $w(x, t)$ are governed by the typical equation of motion

$m_{1} \frac{\partial^{2} w(x, t)}{\partial t^{2}}+E I \frac{\partial^{4} w(x, t)}{\partial x^{4}}={ }^{(c)} F_{v i} \delta(x-c t)$,

for $0 \leq c t \leq L_{b}$.

Many methods for solving this problem were developed and discussed in the literature (see e.g. [2-3]). One of the most well-known techniques is a solution based on the principle of modal superposition [4-6]. The solution Equation (2), represented in the series form, can be expressed as

$$
w(x, t)=\sum_{j} q_{j}(t) \phi_{j}(x), j=1,2, \ldots,
$$

where $\phi_{j}(x)$ is the $j$-th modal shape function and $q_{j}(t)$ is the $j$-th modal amplitude.

For practical applications of a moving axle mass $m_{v i}$ and for $m_{v i} \ll m_{b}$, it is concluded that the solution is of sufficient accuracy even if only the first mode of vibration $(j=1)$ is considered. This solution gives results that well correspond to the evaluated measurements of a dynamic response on real bridges of various structural arrangements. The excitation force ${ }^{(c)} F_{v i}$ in Equation (2) represents the interaction force between the vehicle and the bridge structure. When the kinematic coupling a vehicle - bridge is neglected, the force ${ }^{(c)} F_{v i}$ is simply an applied sprung axle force, (Figure $2 b$ ).

The solution to Equation (2) for a simple beam can be expressed in terms of the modal shapes $\phi_{(1)}(t)$ and associated modal coordinates $q_{(1)}(t)$ considering only the first mode $j=1$. A beam deflection in the subsequent analysis is marked [4, 6] as ${ }^{(c)} q_{(1),\left(F_{v i}\right)}(t) \equiv{ }^{(c)} w_{(1),\left(F_{v i}\right)}\left(L_{b} / 2, t\right)$.

$$
\begin{aligned}
& \left.{ }^{(c)} w_{(1),\left(F_{v i}\right)}\left(L_{b} / 2, t\right)=\frac{\hat{w}(1),\left(F_{v i}\right) s t}{1-{ }^{(c)}} \alpha_{b}^{2} / 2\right) \\
& \times\left(\sin ^{(c)} \Omega_{(1) d r}\left(t-t_{\left(F_{v i}\right)}\right)-{ }^{(c)} \alpha_{1} \sin \omega_{1}\left(t-t_{\left(F_{v i}\right)}\right)\right) \times \\
& \times\left(H\left(t-t_{\left(F_{i}\right)(\text { in })}\right)-H\left(t-t_{\left(F_{i}\right)(o u t)}\right)\right) .
\end{aligned}
$$

The symbols used in Equation (4) have the following meaning: the driving frequency ${ }^{(c)} \Omega_{(1) d r}=\frac{\pi c}{L_{b}}$, the non-dimensional parameter ${ }^{\left({ }^{c}\right)} \alpha_{(1)}=\frac{{ }^{(c)} \Omega_{(1) d r}}{\omega_{(1)}}$, the frequency vibration of the $1^{\text {st }}$ mode of the beam $\omega_{(1)}=\frac{\pi^{2}}{L_{b}^{2}} \sqrt{\frac{E I}{m_{1}}}=\frac{3.14^{2}}{52^{2}} \sqrt{\frac{704802005}{22.16}}=20.56 \mathrm{~s}^{-1}$, the static displacement $\hat{w}_{(1),\left(F_{v i}\right) s t}\left(L_{b} / 2, t\right)=\frac{2 F_{v i} \cdot L_{b}^{3}}{\pi^{4} \cdot E I^{*}}$ due to the axle vehicle forces $F_{v i}$, the modal amplitude $\frac{\hat{w}_{(1)\left(F_{v i}\right) s t}\left(L_{b} / 2\right)}{1-{ }^{(c)} \alpha_{(1)}^{2}}$, and the Heaviside function $H\left(t-t_{\left(F_{i}\right)}\right)$.

\subsection{Impulse load effect ${ }^{(c)} I_{(s F, V e l)}$ arising on the irregularity considering the velocity of the spring compression ${ }^{(c)} \hat{\dot{v}}_{s(\text { sup })}={ }^{(c)} \hat{\vec{v}}_{\text {Irg }}$}

Schematic illustration of the impulse load effect on the irregularity ${ }^{(c)} I_{(s F i, \mathrm{Vel})}$ on the dynamic response is shown in Figure 4.
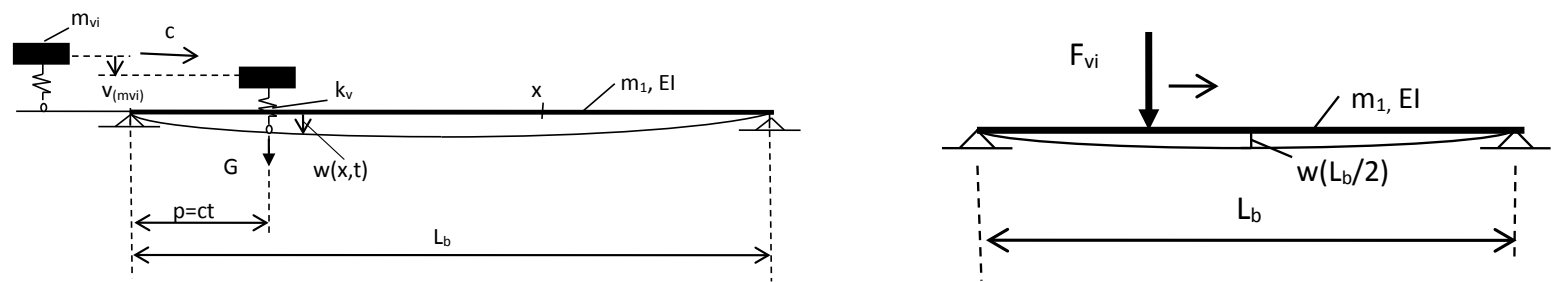

Figure 3 A single axle mass $m_{v i}$ moving over a simple supported beam
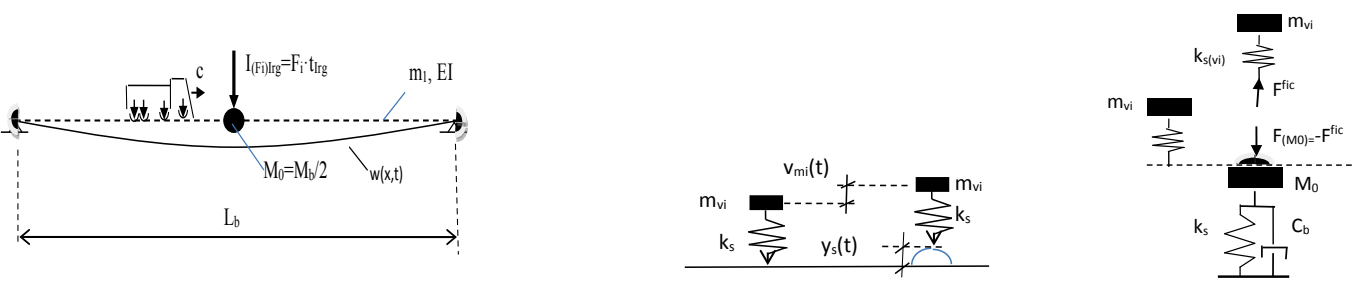

Figure 4 Schematic illustration of the impulse load effect on the irregularity ${ }^{\left({ }^{c}\right)} I_{(s F i, \text { Vel })}$ on the dynamic response 
Table 1 The main parameters used in the simulations

\begin{tabular}{cc} 
Data of the bridge & Data of the vehicle \\
$L_{b}=52 \mathrm{~m}$ & $m_{v}=32 \mathrm{t}$ \\
\hline$A=8.865 \mathrm{~m}^{2}$ & $m_{v 11}=6.37 \mathrm{t}$ \\
$I=10.97 \mathrm{~m}^{4}$ & $m_{v 12}=6.37 \mathrm{t}$ \\
$m_{b, 1}=22.16 \mathrm{t} / \mathrm{m}$ & $m_{v 2}=19.26 \mathrm{t}$ \\
$M_{0}=576.22 \mathrm{t}$ & $k_{s 11}=k_{s 12}=2545.4 \mathrm{kN} / \mathrm{m}$ \\
$E I_{(s b)}^{*}=704802005 \mathrm{kNm}^{2}$ & $k_{s 2}=5091 \mathrm{kN} / \mathrm{m}$ \\
${ }_{(c=70)}^{*} \hat{w}_{(1),\left(F_{v}\right) s t}\left(L_{b} / 2\right)=\frac{2 F_{(v 320)} L_{b}^{3}}{\pi^{4} E I_{(s b)}^{*}}=0.0013$ & \\
$\omega_{(1)}=\frac{\pi^{2}}{L_{b}^{2}} \sqrt{\frac{E I_{(s b)}^{*}}{m_{1}}}=20.56 \mathrm{~s}^{-1}$ & \\
\hline
\end{tabular}

If the sprung mass system $1 D O F_{\left(m_{v i}\right)}$ (a single degree of freedom system) is subjected to the initial displacement ${ }^{\left({ }^{c}\right)} v_{(m v i)}(t=0)=v_{0}$ and the initial velocity $\dot{v}_{\left(m_{v i}\right)}(t=0)=\dot{v}_{0}$, a free vibration displacement ${ }^{(c)} v_{(m v i)}(t)$ of $1 D O F_{(m v i)}$ may be expressed as follows $[2,3]$.

${ }^{(c)} v_{\left(m_{v i}\right)}(t)=e^{-\omega_{b}\left(t-t_{(F i v))}\right.} \frac{\hat{\dot{v}}_{0}}{\omega_{\left(m_{v i}\right)}} \sin \omega_{(m v i)}\left(t-t_{\left(F_{v i}\right)}\right)$.

The displacement amplitude ${ }^{(c)} \hat{v}_{\left(m_{v i}\right)}$ in Equation (5) can be expressed by means of the velocity ${ }^{(c)} \hat{\dot{v}}_{\text {sup }}$ from the impulse theorem

$H_{(m v i)}={ }^{(c)} I_{(m v i)} \ldots \ldots m_{v i}{ }^{(c)} \hat{\dot{v}}_{(m i)}={ }^{(c)} F_{(m v i V e l)}{ }^{(c)} t_{I r g}$.

Thus, the amplitude of velocity from Equation (6) is

${ }^{(c)} \hat{\dot{v}}_{(m i)}=\frac{{ }^{(c)} F_{(m v i \text { Vel })}{ }^{(c)} t_{\text {Irg }}}{m_{v i}}$.

The displacement amplitude ${ }^{(c)} \hat{v}_{(m v i)}$ of $1 D O F_{(m v i)}$ from Equation (5) is expressed by means of the impulse ${ }^{(c)} I_{\left(F m_{v i} \mathrm{Vel}\right)}$, taking into account the rate of deformation (c) $\hat{\dot{v}}_{(m v i)}$ of the suspension:

${ }^{(c)} \hat{v}_{(m v i)}=\frac{\hat{\dot{v}}_{0}}{\omega_{(m v i)}}=\frac{{ }^{(c)} F_{(m v i v e l)}{ }^{(c)} t_{I r g}}{m_{(v i)} \omega_{(m v i)}}=\frac{{ }^{(c)} I_{(F m v i V e l)}}{m_{(v i)} \omega_{(m v i)}}$.

The amplitude of the dynamic deflection ${ }^{(c)} \hat{w}\left(M_{0}\right)\left(I F_{v i} V e l\right)$ for $1 D O F_{\left(M_{0}\right)}$ is expressed by means of a reactive impulse due to the impulse load ${ }^{(c)} I_{\left(F_{v i} \mathrm{Vel}\right)}$, Figure 3.

${ }^{(c)} \hat{w}_{\left(M_{0}\right),(I F v i V e l)}(t)=\frac{{ }^{(c)} I_{\left(F_{v i} V e l\right)}}{\omega_{0} M_{0}}$

A dynamic deflection ${ }^{\left({ }^{c}\right)} \hat{w}_{\left(M_{0}\right)\left(I F_{v i} V e l\right)}(t)$ of $1 D O F_{\left(M_{0}\right)}$, with the amplitude Equation (9), can be expressed in the form $[3,6]$ :

$$
\begin{aligned}
& { }^{(c)} \hat{w}_{\left(M_{0}\right),\left(I F_{v i}, V e l\right)}(t)=\frac{{ }^{(c)} I_{\left(F_{v i}, V e l\right)}}{M_{0} \omega_{0}} e^{-\omega b\left(t-t F_{F i}\right)} \sin \omega_{0} \times \\
& \times\left(t-t_{\left(F_{v i}\right)}\right) \cdot\left(H\left(t-t_{F_{v i}(i n)}\right)-H\left(t-t_{F_{v i}(o u t)}\right)\right) .
\end{aligned}
$$

\subsection{Simulation of the dynamic deflections} for crossing of the three axle heavy truck ${ }^{(c=70)} F_{(v 320)}=320 \mathrm{kN}$ with the speed $\boldsymbol{c}=\mathbf{7 0}$ $\mathbf{k m} / \mathbf{h}=\mathbf{1 9 . 4 4} \mathrm{m} / \mathrm{sand}$ the rate of deformation ${ }^{(c=70)} \hat{\dot{y}}_{\text {Irg }}=9.33 \mathrm{~m} / \mathrm{s},{ }^{(c=70)} t_{\text {Irg }}=\frac{0.5}{19.44}=0.0257$

for time $t>t_{\text {Irg }}$

The total dynamic displacement of the bridge due to moving an axle mass $m_{v i}$ at the speed $c=70 \mathrm{~km} / \mathrm{h}=19.44 \mathrm{~m} / \mathrm{s}$ is obtained by superposition from Equation (1). In the subsequent analyses the components of the dynamic response ${ }^{(c)} w_{(1),\left(F_{v i}\right)}\left(L_{b} / 2, t\right)$ and ${ }^{(c)} w_{\left(M_{0}\right),(I F v i V e l)}(t)$, the total dynamic deflection ${ }^{(c)} w_{\left(F_{v i}+I F_{v i} V_{e l}\right)}\left(L_{b} / 2, t\right)$ and the dynamic coefficient ${ }^{(c)} \delta_{d y n\left(F_{v i}+s F_{v i} V e l\right)}\left(L_{b} / 2, t\right)$ are presented. The results of dynamic displacements from the above analytical relationships are presented graphically [8].

\section{Input parameters}

The main parameters used in the simulations are shown in Table 1.

Kinematic quantities ${ }^{(c)} y_{\text {Irg }}(t),{ }^{(c)} \dot{y}_{\text {Irg }}(t)$ for the irregularity in the form of a parabolic plank, $l_{I r g}=0.50 \mathrm{~m}, h_{I r g}=0.6 \mathrm{~m}$, required for formulating an impulse load effect on the irregularity ${ }^{(c)} I_{\left(F_{i}, V e l\right)}$, for the speed $c=70 \mathrm{~km} / \mathrm{h}$, are:

$$
\begin{aligned}
& { }^{(c=70)} y_{\text {Irg }}(t)=-0.96 c^{2} t^{2}+0.48 c t=-0.96 \times \\
& \times 19.44^{2} t^{2}+0.48 \cdot 19.44 t=-362.8 t^{2}+9.33 t, \\
& { }^{(c=70)} \dot{y}_{\text {Irg }}(t)=-1.92 \cdot c^{2} t+0.48 c=-1.92 \times \\
& \times 19.44^{2} t+0.48 \cdot 19.44=-725.59 t+9.33 .
\end{aligned}
$$

\section{Characteristics of an impulse effect for the axle}

force $F_{(v 11)}=63.7 \mathrm{kN}$

- Compression of the spring ${ }^{(c=70)} \hat{v}_{(\sup V e l)}$ due to the velocity ${ }^{(c=70)} \hat{\dot{v}}_{\text {sup }}=9.33 \mathrm{~m} / \mathrm{s}$ and

$$
\begin{aligned}
& { }^{(c=70)} \hat{v}_{(\text {sup, Vel })}={ }^{(c=70)} \hat{\dot{v}}_{\text {sup }}{ }^{\left({ }^{(}=70\right)} t_{(\text {hrg })}= \\
& =9.33 \cdot 0.0257=0.2398 \mathrm{~m},
\end{aligned}
$$


- Force in the spring ${ }^{(c=70)} F_{11\left(v_{\text {sup }} V e l\right)}$ due to the compression in the spring ${ }^{(c=70)} \hat{v}_{(\text {sup }, \text { Vel })}$

$$
\begin{aligned}
& { }^{(c=70)} F_{11(v \text { sup Vel })}=\frac{F_{v 11}{ }^{(c=70)} \hat{v}_{(\text {sup }, \text { Vel })}}{t_{\text {Irg }}}= \\
& \frac{63.7 \cdot 0.2398}{0.06}=254.56 \mathrm{kN},
\end{aligned}
$$

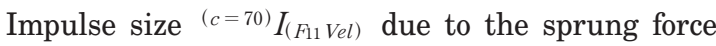
${ }^{(c=70)} F_{11\left(v_{\text {sup }} V e l\right)}$ acting on the spring of $1 D O F_{(m v i)}$

$$
\begin{aligned}
& { }^{(c=70)} I_{\left(F_{v 11} \mathrm{Vel}\right)}={ }^{(c=70)} F_{11\left(v_{\text {sup } V e l)}{ }^{(c=70)}\right.} t_{I r g}= \\
& =254.56 \cdot 0.0257=6.5422 \mathrm{kNs},
\end{aligned},
$$

- Amplitude of displacement ${ }^{(c=70)} \hat{w}_{\left(M_{0}\right),\left(I F_{v 11} \text { Vel }\right)}(t)$ acting on the spring of $1 D O F_{\left(m_{v i}\right)}$

$$
\begin{aligned}
& { }^{(c=70)} \hat{v}_{\left(F_{v 11} V e l\right)}=\frac{{ }^{(c=70)} I_{\left(F_{v 11} V e l\right)}}{\omega_{(m v 11)} m_{(v 11)}}=\frac{6.5422}{20 \cdot 6.37}= \\
& =0.0513 \mathrm{~m},
\end{aligned}
$$

- Amplitude ${ }^{(c=70)} \hat{w}_{\left(M_{0}\right),\left(F_{v 11} \text { Vel }\right)}(t)$ acting on the spring of $1 D O F_{\left(M_{0}\right)}$ for the impulse ${ }^{(c=70)} I_{\left(F_{11} \mathrm{Vel}\right)}=6.5422 \mathrm{kNs}$

$$
\begin{aligned}
& { }^{(c=70)} \hat{w}_{\left(M_{0}\right),\left(I F_{v 11} \mathrm{Vel}\right)}(t)=\frac{{ }^{(c=70)} I_{\left(F_{v 11} \mathrm{Vel}\right)}}{\omega_{0} M_{0}}= \\
& =\frac{6.5422}{20.43 \cdot 576.16}=0.00056 \mathrm{~m} .
\end{aligned}
$$

Characteristics of an impulse effect for the axle force ${ }^{(c=70)} F_{(v 2)}=192.6 \mathrm{kN}$ is obtained analogously as for Equations (13) to (17).

Requirement of the same amplitudes of the deflection of continuous beam $\hat{w}_{(F v 320) s t}\left(L_{b} / 2, t\right)$ for the span No. 5 from the static calculation of the bridge is $\hat{w}_{(F v 320) s t}\left(L_{b} / 2, t\right)=0.00133 \mathrm{~m}$. The deflection of fictive simple beam $\hat{w}_{(F v 32) s t}\left(L_{b} / 2, t\right)$, with the fictive bending stiffness $E I_{(s b)}^{*}$, for the force $F_{v}=320 \mathrm{kN}$ it is image in Figure 5 .

$$
\begin{aligned}
& E I_{(s b)}^{*}=\frac{F_{v} L_{(5)}^{3}}{48 \cdot w_{\left(F_{v}\right),(L b 5)}(x, p)}= \\
& =\frac{320 \cdot 52^{3}}{48 \cdot 0.00133}=704802005 \mathrm{kNm}^{2} .
\end{aligned}
$$

\subsubsection{Time history of the dynamic deflections} ${ }^{(c)} w_{\left(F_{v i}+I F_{v i} V e l\right)}\left(L_{b} / 2, t\right)$ due to the moving load $F_{v i}$ for a time $t>t_{\text {Irg }}$

The dynamic deflections of the mid-span ${ }^{(c)} w_{\left(F_{v i}+I F_{v i} V e l\right)}\left(L_{b} / 2, t\right)$ from Equation (1) are applied for the speed $c=70 \mathrm{~km} / \mathrm{h}=19.44 \mathrm{~m} / \mathrm{s}$ :

$$
\begin{aligned}
& { }^{(c=70)} w_{\left(F_{v i}+I_{s F v i} V e l\right)}\left(L_{b} / 2, t\right)= \\
& ={ }^{(c=70)} w_{(1),(F v i)}\left(L_{b} / 2, t\right)+{ }^{(c=70)} w_{\left(M_{0}\right)(I S F v i V e l)}(t) .
\end{aligned}
$$

3.3.1-1 Dynamic deflections ${ }^{(c)} w_{(1),\left(F_{v 320}\right)}\left(L_{b} / 2, t\right)$ due to the moving axle load $F_{v 11}, F_{v 12}, F_{v 2}$

a) Components of deflection

${ }^{(c=70)} w_{(1),\left(F_{v 11}\right)}\left(L_{b} / 2, t\right),{ }^{(c=70)} w_{(1),\left(F_{v 12}\right)}\left(L_{b} / 2, t\right)$, ${ }^{(c=70)} w_{(1),\left(F_{v 2}\right)}\left(L_{b} / 2, t\right)$ belonging to axle loads,

Figure 6.

b) Total deflection of the beam ${ }^{(c=70)} w_{(1),\left(F_{v 320}\right)}\left(L_{b} / 2, t\right) \equiv{ }^{(c=70)} q_{(1),\left(F_{v 11}+F_{v 12}+F_{v 2}\right)}(t)$

belong to the moving axle load

$F_{v 320}=F_{v 11}+F_{v 12}+F_{v 2}$, Figure 7 .

$$
\begin{aligned}
& { }^{(c=70)} w_{(1),\left(F_{v 320}\right)}\left(L_{b} / 2, t\right)={ }^{(c=70)} w_{(1),\left(F_{v 11}\right)}\left(L_{b} / 2, t\right)+ \\
& +{ }^{(c=70)} w_{(1),\left(F_{v 12}\right)}\left(L_{b} / 2, t\right)+{ }^{(c=70)} w_{(1),\left(F_{v 2}\right)}\left(L_{b} / 2, t\right)
\end{aligned}
$$

3.3.1-2 Dynamic deflections ${ }^{(c=70)} w_{\left(M_{0}\right),(I F v 320)}\left(L_{b} / 2, t\right)$ due to the impulse load on the irregularity $I_{(v 320)}=I_{(v 11)}+I_{(v 12)}+I_{(v 2)}$

Input characteristics are given from Equations (13) to (17).

a) Components of dynamic deflection

${ }^{(c=70)} w_{\left(M_{0}\right),\left(I F_{v 11} \mathrm{Vel}\right)}(t),{ }^{(c=70)} w_{\left(M_{0}\right),\left(I F_{v 12} \mathrm{Vel}\right)}(t)$,

${ }^{(c=70)} w_{\left(M_{0}\right),\left(I F_{v 2} \text { Vel }\right)}(t)$ belong to the impulse load,

Figure 8.

b) Total displacement ${ }^{(c=70)} w_{\left(M_{0}\right),(I F 320 \mathrm{Vel})}(t)$ belong to the impulse load $F_{v}=320 \mathrm{kN}$ ${ }^{(c=70)} w_{\left(M_{0}\right),(I F 320 \mathrm{Vel})}(t)={ }^{(c=70)} w_{\left(M_{0}\right),(I F v 11 \mathrm{Vel})}(t)+$ $+{ }^{(c=70)} w_{\left(M_{0}\right),\left(I F_{v 12} \mathrm{Vel}\right)}(t)+{ }^{(c=70)} w_{\left(M_{0}\right),\left(I F_{v 2} \mathrm{Vel}\right)}(t)$,

Figure 9 .
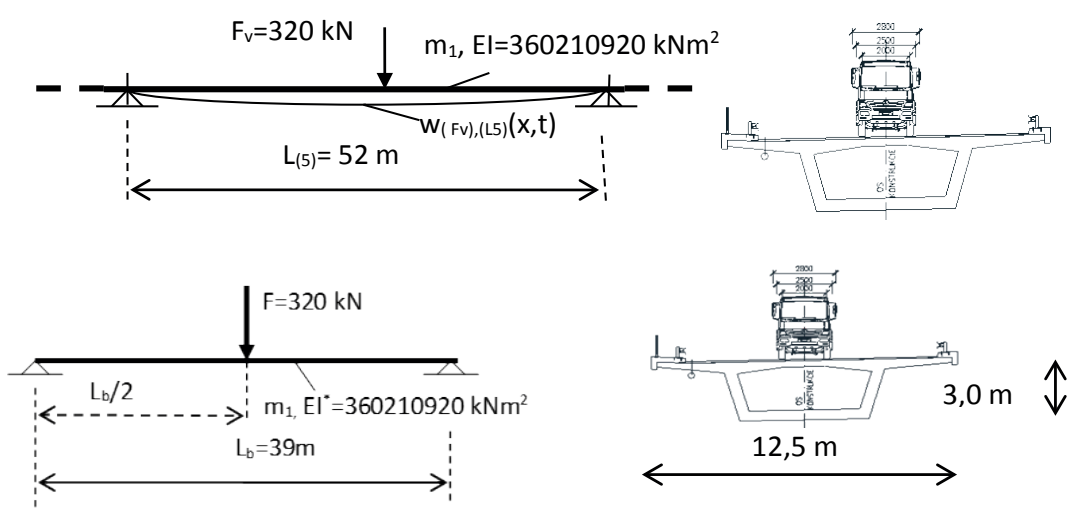

Figure 5 Associated fictitious simple beam for the analysis of the 5th span of bridge with the reduced bending stiffness $E I_{(s b)}^{*}$ 


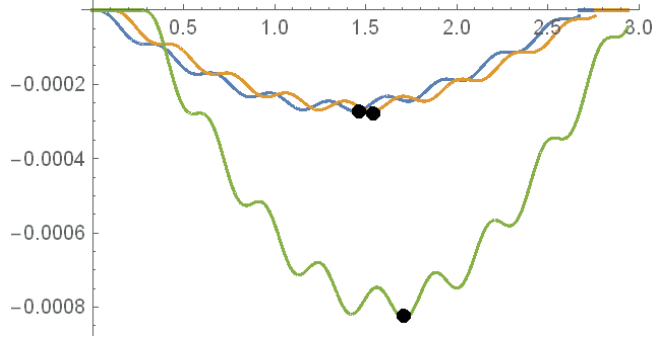

$0.00027 m, 0.00027 m, 0.0008 m$

Figure 6 Axes: $x=t[s], y=$ Components of deflection ${ }^{(c=70)} w_{(1),\left(F_{v 11}\right)}\left(L_{b} / 2, t\right),{ }^{(c=70)} w_{(1),\left(F_{v 12}\right)}\left(L_{b} / 2, t\right)$, ${ }^{(c=70)} w_{(1),\left(F_{v 2}\right)}\left(L_{b} / 2, t\right)[m]$ belonging to axle loads $F_{v 11}$, $F_{v 12}, F_{v 2}$

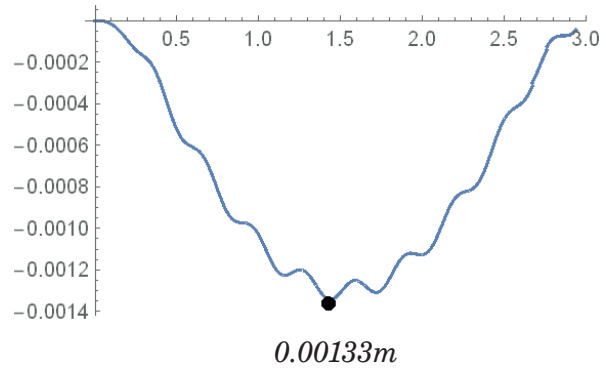

Figure 7 Axes: $x=t[s], y={ }^{(c=70)} w_{(1),\left(F_{v 320}\right)}\left(L_{b} / 2, t\right)$ [m], Total amplitude of deflection ${ }^{(c=70)} \hat{w}_{(1),\left(F_{v} 320\right)}\left(L_{b} / 2\right)=0.00133 \mathrm{~m}$

\subsubsection{Aggregate force effects acting on the beam} deflection $\left.{ }^{(c=70)} w_{\left(M_{0}\right),\left(F_{v 3} 30+I F_{3} 320\right.} \mathrm{Vel}\right)\left(L_{b} / 2, t\right)$

Aggregate force effects from Equation (19) for the whole truck obtain by the superposition of the moving load ${ }^{(c=70)} w_{(1),\left(F_{v 320}\right)}\left(L_{b} / 2, t\right)$ and the impulse load on the irregularity ${ }^{(c=70)} w_{\left(M_{0}\right),(I F v 320 \mathrm{Vel})}\left(L_{b} / 2, t\right)$.

a) Components ${ }^{(c=70)} w_{(1),\left(F_{v 320}\right)}\left(L_{b} / 2, t\right)$,

${ }^{(c=70)} w_{\left(M_{0}\right),\left(I F_{v 320} \mathrm{Vel}\right)}\left(L_{b} / 2, t\right)$, Figure 10

b) Aggregate beam deflection

$$
\begin{aligned}
& { }^{(c=70)} w_{\left(M_{0}\right),\left(F_{v 3} 30+I S F_{v 3} 30 \mathrm{Vel}\right)}\left(L_{b} / 2, t\right) \\
& { }^{(c=70)} w_{\left(M_{0}\right),\left(F_{v} 320+I s F_{v 3} 30 \mathrm{Vel}\right)}\left(L_{b} / 2, t\right)= \\
& ={ }^{(c=70)} w_{(1),\left(F_{v 3} 320\right)}\left(L_{b} / 2, t\right)+{ }^{(c=70)} w_{\left(M_{0}\right),\left(\text { IsF } F_{v} 320 \mathrm{Vel}\right)}(t)
\end{aligned}
$$

Figure 11.

\subsubsection{Dynamic impact factor (DAF)}

$$
{ }^{(c=70)} \boldsymbol{\delta}_{d y n\left(F_{v 320}+I F_{v} 320 \mathrm{Vel}\right)}\left(L_{b} / 2, t\right) \text { for the beam }
$$

\section{deflection}

${ }^{(c=70)} \delta_{d y n\left(F_{v 320}+I F v 320 \mathrm{Vel}\right)}\left(L_{b} / 2, t\right)=$

$\frac{{ }^{(c=70)} w_{\left(F_{v 320}+I F_{v 320} \mathrm{Vel}\right) \max }\left(L_{b} / 2, t\right)}{{ }^{(c=70)} w_{(1),\left(F_{v} 320\right) s t}\left(L_{b} / 2, t\right)}$, Figure 12.

All the graphical solution (Figures 6 to 12) are the outputs from [8].

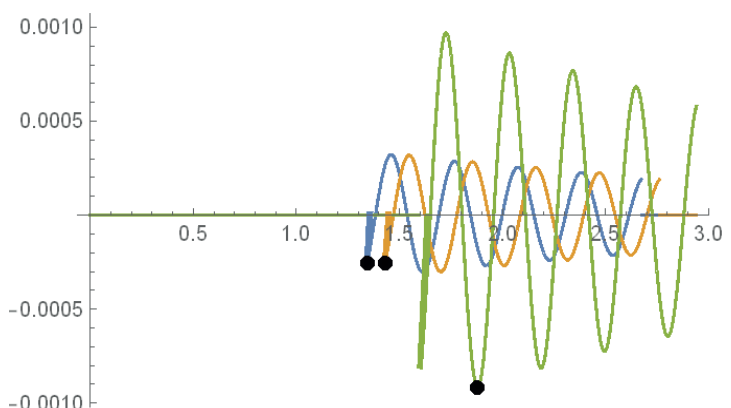

$0.00027 m, 0.00027 m, 0.0009 m$

Figure 8 Axes: $x=t[s], y=$ Components belong to the impulse load ${ }^{(c=70)} w_{\left(M_{0}\right),\left(I F_{v 11} V e l\right)}(t),{ }^{(c=70)} w_{\left(M_{0}\right),\left(I F_{v 12} V e l\right)}(t)$,

$$
{ }^{(c=70)} w_{\left(M_{0}\right),\left(I F_{v 2} \mathrm{Vel}\right)}(t)[\mathrm{m}]
$$

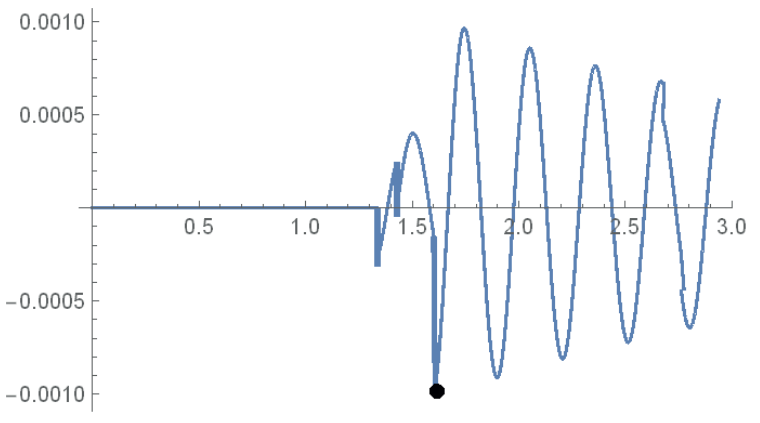

Figure 9 Axes: $x=t[s], y={ }^{(c=70)} w_{\left(M_{0}\right),(I F 320 \mathrm{Vel})}(t) \quad[\mathrm{m}]$, Amplitude ${ }^{(c=70)} \hat{w}_{\left(M_{0}\right),(I F 320 \mathrm{Vel})}=0.001 \mathrm{~m}$

4 Dynamic load test of the 10-span RC highway bridge for passing a heavy truck $F_{v}=320 \mathrm{kN}$ over the standard irregularity for the speed $c=70 \mathrm{~km} / \mathrm{h}$

In the previous section the dynamic response of a fictitious simple beam of length $L_{b}=52 \mathrm{~m}$ with the flexural stiffness $E I_{(s b)}^{*}$, corresponding to the characteristic span $L_{b i}=52 \mathrm{~m}$ of the ten-span continuous bridge, was analysed. In this section some results are presented from the dynamic testing of the 10-span highway bridge corresponding to the passage of a heavy testing vehicle with the total mass $m_{v}=32 \mathrm{t}$ passing the bridge with a standard irregularity at speed $c=70 \mathrm{~km} / \mathrm{h}=19.44 \mathrm{~m} / \mathrm{s}$ (the identical truck as in the numerical modelling), Figure 13. Dynamic tests were performed in accordance with standard [1].

\subsection{Dynamic deflection ${ }^{(c=70)} w_{\left(F_{v} 320\right)}^{o b s}\left(L_{(b 5)} / 2, t\right)$ at} the mid-span No. 5 due to crossing of the heavy truck $F_{v}=32 \mathrm{t}$ - the irregularity located in the middle of span No. $5, c=70 \mathrm{~km} / \mathrm{h}$

The time history of the dynamic deflection at the mid-span No. $5{ }^{(c=70)} w_{\left(F_{v} 320\right)}^{o b s}\left(L_{(b 5)} / 2, t\right)$ from [7] is shown in Figures 14, 15. 


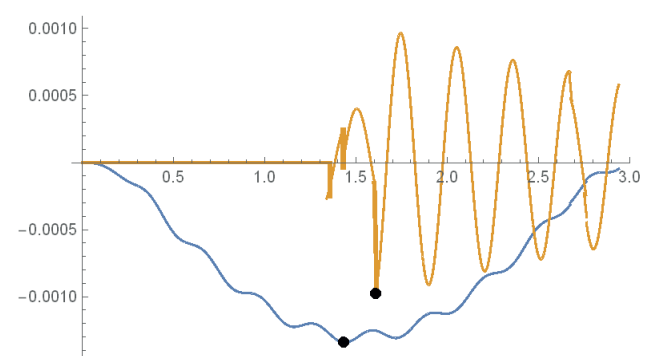

Figure 10 Axes: $x=t[s], y=$ Components $\left.{ }^{(c=70)} w_{(1),\left(F_{v 320}\right)}\left(L_{b} / 2, t\right),{ }^{(c=70)} w_{\left(M_{0}\right),(I S F r 320} \mathrm{Vel}\right)(t)$ [m], Amplitudes ${ }^{(c=70)} \hat{w}_{(1),\left(F_{v 320}\right)}=0.00133 \mathrm{~m}$, ${ }^{(c=70)} \hat{w}_{\left(M_{0}\right),(I F 320 \mathrm{Vel})}=0.001 \mathrm{~m}$

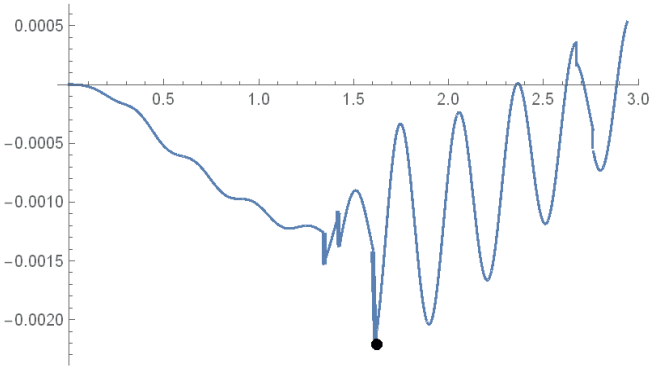

Figure 11 Axes: $x=t[s], y=$ $\left.{ }^{(c=70)} w_{(M 0),\left(F_{v 3} 320\right.}+I F_{v 320} \mathrm{Vel}\right)\left(L_{b} / 2, t\right)[\mathrm{m}]$, Amplitude ${ }^{(c=70)} \hat{w}_{\left(M_{0}\right),\left(F_{v} 320+I F_{v} 320 \mathrm{Vel}\right)}=0.0022 \mathrm{~m}$

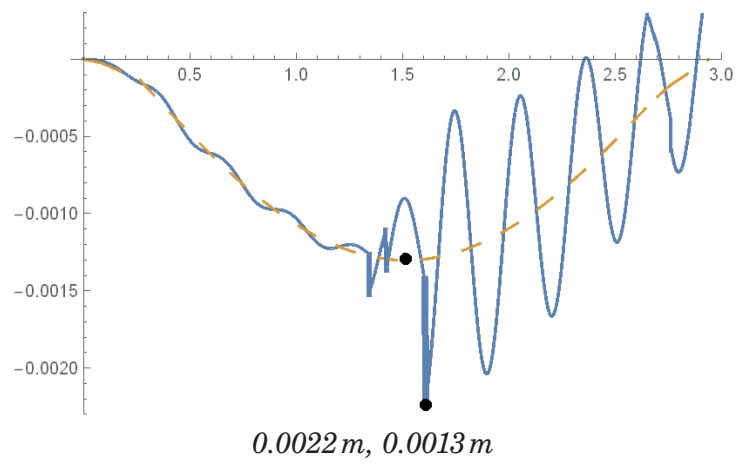

Figure 12 Axes: $x=t[s], y=(D A F){ }^{(c=70)} \boldsymbol{\delta}_{d y n\left(F_{v} 320+I F_{v} 320\right.} \mathrm{Vel}\left(L_{b} / 2, t\right)[$.$] ,$

${ }^{(c=70)} \boldsymbol{\delta}_{d y n\left(F_{0320}+I F_{3320} \mathrm{Vel}\right)}\left(L_{b} / 2, t\right)=\frac{{ }^{(c=70)} w_{\left(F_{F 320}+I F_{v 320} \mathrm{Vel}\right) \max }\left(L_{b} / 2, t\right)}{{ }^{(c=70)} w_{(1),\left(F_{v 320}\right) t}\left(L_{b} / 2, t\right)}=\frac{0.0022}{0.0013}=1.69$
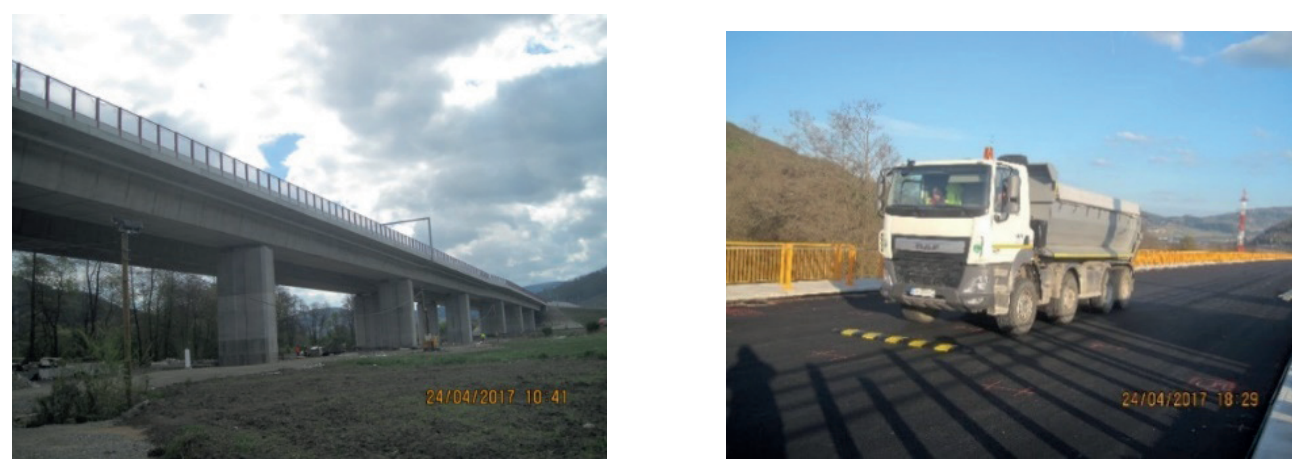

Figure 13 Dynamic load test of the Zvolen-Pstrusa highway bridge subjected to the heavy truck $F_{v}=320 \mathrm{kN}$ passing over the standard irregularity

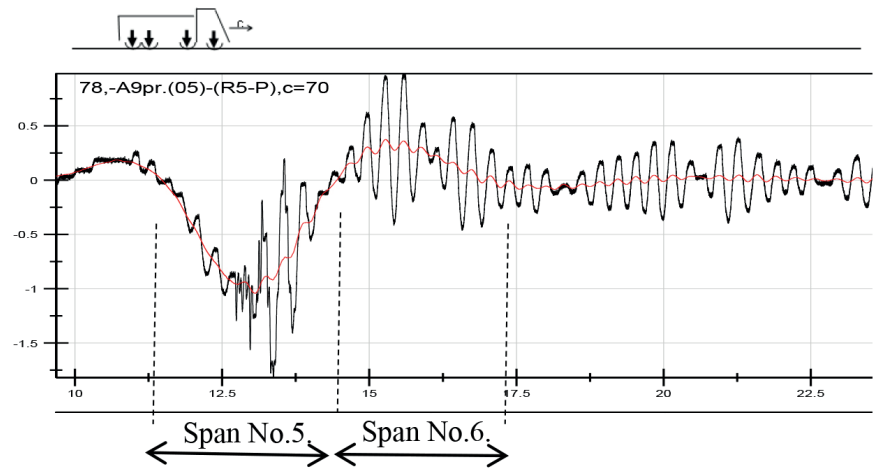

Measured dynamic amplifier factor for the $5^{\text {th }}$ span ${ }^{(c=70)} w_{\left(F_{v} 320\right)}^{o b s}\left(L_{(b 5)} / 2, t\right)=\frac{1.75}{1.04}=1.68$

Figure 14 The time history of the dynamic deflection ${ }^{(c=70)} w_{\left(F_{v} 320\right)}^{o b s}\left(L_{(b 5)} / 2, t\right)$ at the mid-span No. 5 of the ten-span tested continuous bridge for $c=70 \mathrm{~km} / \mathrm{h}$ - The standard irregularity located in the middle of span No. 5 
Frequency composition - dominant frequencies from the absolute transducer
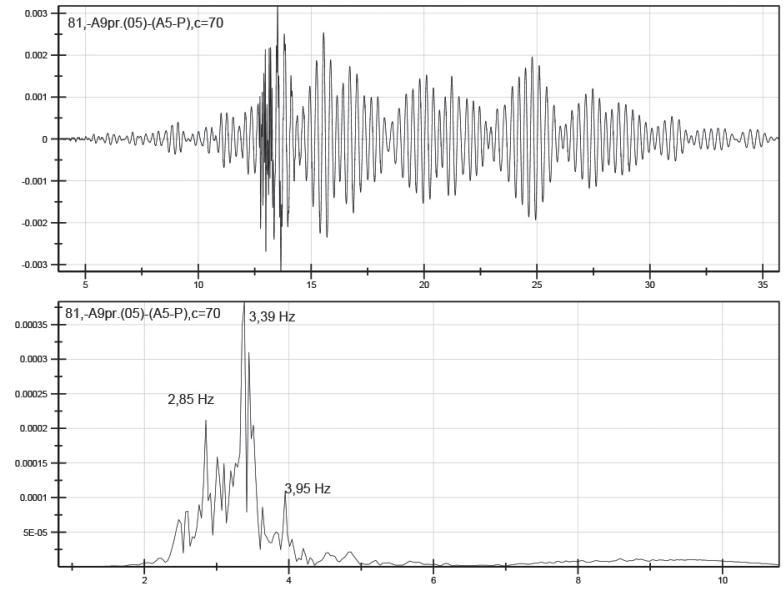

$f_{(1)}^{o b s}=2.85 \mathrm{~Hz}, f_{(2)}^{o b s}=f_{\max }^{o b s}=3.39 \mathrm{~Hz} \rightarrow \omega_{\max }^{o b s}=21.29 \mathrm{~s}^{-1}$

Theoretical first circular frequency of the fictive beam $L_{b}=52 \mathrm{~m}$ used in numerical

$$
\text { simulation is } \omega_{(1)}=\frac{\pi^{2}}{L_{b}^{2}} \sqrt{\frac{E I_{(s b)}^{*}}{m_{1}}}=20.56 \mathrm{~s}^{-1}
$$

Figure 15 Frequency composition of the dynamic deflection of the measured continuous

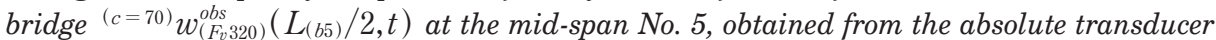

\section{Conclusions}

One of the purposes of the numerical modelling was to verify the proposed simplified solution of ae dynamic response of the characteristic span bridge structure as a response of a simple beam.

(1) Comparison of numerical modelling of the response to the girder and experimental testing on a continuous bridge structure for a speed of $70 \mathrm{~km} /$ $\mathrm{h}$ shows a good agreement between the two results.

(2) Evaluate the intense dynamic response due to the moving of the heavy truck as an impact of the impulse load arising on the irregularity:

- Smooth passes of the test vehicle show low DAV values ${ }^{(c=70)} \delta_{d y n\left(F_{v 320}\right)}^{\text {sim }}\left(L_{b} / 2, t\right)=1.03$. Passes of the tested vehicle over the bridge with the standard irregularity for the speed $c=70 \mathrm{~km} / \mathrm{h}$ gives the strong response of the bridge. Measured dynamic amplifier factor for the $5^{\text {th }}$ span ${ }^{(c=70)} w_{\left(F_{v 320}\right)}^{o b s}\left(L_{(b 5)} / 2 t\right)=\frac{1.75}{1.04}=1.68$

- Simulation DAF from the Section 3.3.3 gave the value of $\mathrm{DAF}^{\left({ }^{(c=70)} \boldsymbol{\delta}_{d y n}^{(\operatorname{sim})} F_{v 320}+I F_{3320} \mathrm{Vel}\right)}\left(L_{b} / 2, t\right)=1.69$

- The ratio of DAFs for the pass of the tested vehicle over the bridge with the standard irregularity and the smooth pass gives the value $\frac{{ }^{(c=70)} \delta_{d y n}^{\left.o b F_{v} 320, \mathrm{Vel}\right)}\left(L_{b} / 2, t\right)}{{ }^{(c=70)} \delta_{d y n\left(F_{v 320}\right)}^{(\operatorname{sim})}\left(L_{b} / 2, t\right)}=\frac{1.68}{1.03}=1.64$.

- The performed numerical simulation allows to evaluate also a dynamic coefficient of the force effect ${ }^{(c=70)} \Delta_{d y n\left(F_{v i}\right)}^{(F o r e)}$ :

For the front axle force $F_{(v 11)}=63.7 \mathrm{kN}$ :.

${ }^{(c=70)} \Delta_{d y n\left(F_{v} 11\right)}^{(F o r e)}=\frac{{ }^{(c=70)} F_{(v 11 \mathrm{Vel})}}{F_{(v 11)}}=\frac{254}{63.7}=4.0$.

For the axle force $F_{(v 2)}=192.6 \mathrm{kN}$ :

${ }^{(c=70)} \Delta_{d y n\left(F_{v 2}\right)}^{(F o r e)}=\frac{{ }_{(c=70)} F_{(v 2 \mathrm{Vel})}}{F_{(v 2)}}=\frac{769.76}{192.6}=4.0$.

By a dynamic coefficient of the force effect ${ }^{(c=70)} \Delta_{d y n\left(F_{v i}\right)}^{(F o r c e)}$ one can determine a theoretical dynamic force $^{(c)} F_{(v i) d y n}={ }^{(c=70)} \Delta_{d y n(F v i)}^{(F o r c e)} F_{(v i)}$. This result confirms the experimental measurement of the dynamic response on the bridge.

\section{Acknowledgment}

Presented result were obtained with the support of project VEGA No. 12/0045/19, Slovak Republic.

\section{References}

[1] CSN 73 6209: Loading tests of bridges (in Czech). Prague: Standard CNI, 1996.

[2] BIGGS, J. M. Introduction to structural dynamics. New York: Mc Graw-Hill, 1964. ISBN 978-0070052550.

[3] KOLOUSEK, V. Dynamics of building structures (in Czech). Prague: SNTL, 1954.

[4] MORAVCIK, M., MORAVCIK, M. Resonance vibration of railway bridges subjected to passing vehicles. Communications - Scientific Letters of the University of Zilina [online]. 2017, 19(3), p. 96-101. ISSN 1335-4205, ISSN 2585-7878. Available from: http://komunikacie.uniza.sk/index.php/communications/article/view/241

[5] FRYBA, L. Vibration of solids and structures under moving loads. London: Telford, 1999. ISBN 0-7277-2741-9. 
[6] YANG, Y. B., LIN, C. W. Vehicle bridge interaction dynamics and potential application. Journal of Sound and Vibration [online]. 2005, 284(1-2), p. 205-226. ISSN 0022-460X. Available from: https://doi.org/10.1016/j. jsv.2004.06.032

[7] MORAVCIK, M. Dynamic load test of a road bridge on R2 Zvolen-Pstrusa (in Slovak). Report. Zilina: University of Zilina, 2017.

[8] Wolfram Mathematics. Version 10.3.1. 